\title{
Placental Site Trophoblastic Tumor: A Rare Pathological Entity
}

\author{
Anitha Seervi ${ }^{1}$, Neha Sethi ${ }^{2}$, Sangeeta Hudda ${ }^{3}$, Jaya Choudhary ${ }^{4}$, Maneesh K Vijay ${ }^{5}$, Chetna Mehrol ${ }^{6}, \mathrm{M} \mathrm{L} \mathrm{Yadav}^{7}$, \\ Manju Raghava ${ }^{8}$
}

\begin{abstract}
Placental site trophoblastic tumor (PSTT) is a very rare type of gestational trophoblastic neoplasm that originates from the placental implantation site. They occur mainly in women who have a history of abortion, ectopic pregnancy, or molar pregnancy. Here, we report a case of PSTT in a 35-year-old P6L6 female who presented with complaints of continuous bleeding per vagina and spotting for 8 months and underwent three times dilatation and evacuation for retained products of conception. The patient underwent exploratory laparotomy but the patient still had a history of pain abdomen and bleeding per vagina. On biochemical evaluation, the patient had raised beta-hCG levels. Contrast-enhanced computed tomography scan (CECT) lower abdomen revealed bulky uterus and heterogeneous hemorrhagic areas in the endometrium with right tube ovarian mass. Endometrial biopsy was done which showed retained gestational tissue and no chorionic villi. Then patient underwent a total abdominal hysterectomy with bilateral salpingectomy. The final diagnosis of PSTT was made on the basis of the clinical picture and morphological features. Keywords: CC, Gestation, GTN, hCG, Histopathology, PSTT.

Journal of Mahatma Gandhi University of Medical Sciences \& Technology (2021): 10.5005/jp-journals-10057-0180
\end{abstract}

\section{INTRODUCTION}

Placental site trophoblastic tumor (PSTT) is a very rare type of aggressive gestational trophoblastic neoplasm (GTN) that accounts for $1-2 \%$ of all GTNs. ${ }^{1}$ Its incidence is approximately 1 per $1,00,000$ pregnancies. ${ }^{1}$ It was first described by Kurman and Scully in 1976 as a trophoblastic pseudotumor. It originates from the placental implantation site. Approximately 300 cases of PSTT have been reported as per literature. ${ }^{2}$ Because of its rarity, the etiology of PSTT is not yet fully understood.

Placental site trophoblastic tumor differs from another gestational trophoblastic neoplasm as it produces less amount of beta-human chorionic gonadotropin. It has slow growth and is relatively resistant to chemotherapy. ${ }^{3}$

\section{Case Report}

A 35-year-old P6L6 female presented with complaints of continuous bleeding PV and spotting for 8 months. The patient underwent three therapeutic dilatation and evacuation for retained products of conception. The patient underwent exploratory laparotomy but the patient still had a history of pain abdomen and bleeding per vagina. On biochemical evaluation, the patient had raised betahCG levels (900 IU/L). CECT of the lower abdomen was done which revealed bulky uterus and heterogeneous hemorrhagic areas in the endometrium with right tube ovarian mass. Endometrial biopsy was done which showed retained gestational tissue and no chorionic villi. Then patient had undergone a total abdominal hysterectomy with bilateral salpingectomy (Fig. 1).

On gross examination, hemorrhagic mass was identified measuring $3.2 \times 3.2 \times 2.8 \mathrm{~cm}$ involving the endometrial cavity (Fig. 2). Microscopically, intermediate trophoblasts with scattered multinucleated syncytiotrophoblasts are seen. Tumor cells are infiltrating the myometrial fibers (Fig. 3). These tumor cells were usually large and polygonal with irregular vesicular nuclei and displayed an abundance of dense eosinophilic to

\footnotetext{
${ }^{1-8}$ Department of Pathology, Mahatma Gandhi Medical College and Hospital, Jaipur, Rajasthan, India

Corresponding Author: Anitha Seervi, Department of Pathology, Mahatma Gandhi Medical College and Hospital, Jaipur, Rajasthan, India, Phone: +91 9460276203, e-mail: anithachowdhary5@gmail.com How to cite this article: Seervi A, Sethi N, Hudda S, et al. Placental Site Trophoblastic Tumor: A Rare Pathological Entity. J Mahatma Gandhi Univ Med Sci Tech 2021;6(3):82-84.

Source of support: Nil

Conflict of interest: None
}

amphophilic cytoplasm. Abundant extracellular fibrinoid material was seen on occasion. At places cells appear to replace the vascular wall (Fig. 4). No mitosis was identified. On the basis of characteristic morphological features and clinical picture, final diagnosis of PSTT was made and other trophoblastic tumors were excluded.

pTNM staging was PT1. Now the patient is lost to follow-up.

\section{Discussion}

Placental site trophoblastic tumor is a very rare variant of gestational trophoblastic neoplasm. It is a tumor of intermediate trophoblasts with malignant potential. Its incidence is approximately 1 per 1, 00,000 pregnancies. ${ }^{1}$ It mainly affects women of childbearing age. It can occur after abortions, normal pregnancy, ectopic pregnancy, molar pregnancy etc. ${ }^{4}$ The most common symptoms are vaginal bleeding followed by amenorrhea. The $\beta$-hCG serum levels may vary, but they are often on the lower side than those seen in cases of choriocarcinoma. The macroscopic examination shows that the tumors have localized nodules or polypoid tumors protruding into the uterine cavity. The cut surface is soft and tan and contains areas of hemorrhage and necrosis. It may also present as masses infiltrating the myometrium along with indistinct margins. On 
histopathological examination, PSTT consists of proliferating sheets of intermediate trophoblasts with a prominent predilection to invade blood vessels. The cells are polygonal with dense eosinophilic cytoplasm and large atypical nuclei. Neither syncytiotrophoblasts nor chorionic villi are seen. A characteristic of tumor growth is diffuse infiltration. Clumps of tumor cells may invade muscle fibers. In comparison to choriocarcinoma, tumor cells in PSTT show less necrosis and hemorrhage while having a tendency to spread through lymphatics. ${ }^{5,6}$ The tumor is confined to the uterine corpus usually and about $10 \%$ of cases are malignant. The standard treatment for patients with localized PSTT is total abdominal hysterectomy with or without salpingo-ophorectomy. ${ }^{4}$ Prognosis depends on the stage of the primary tumor, the period of time between the last pregnancy

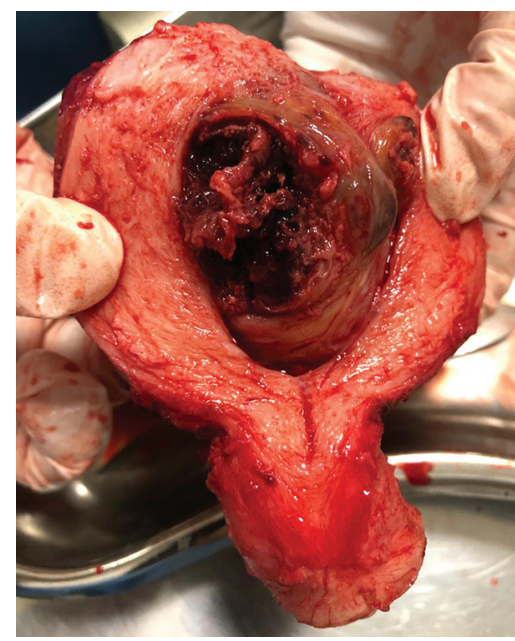

Fig. 1: Hysterectomy specimen: Perioperative photo showing hemorrhagic mass in the endometrial cavity

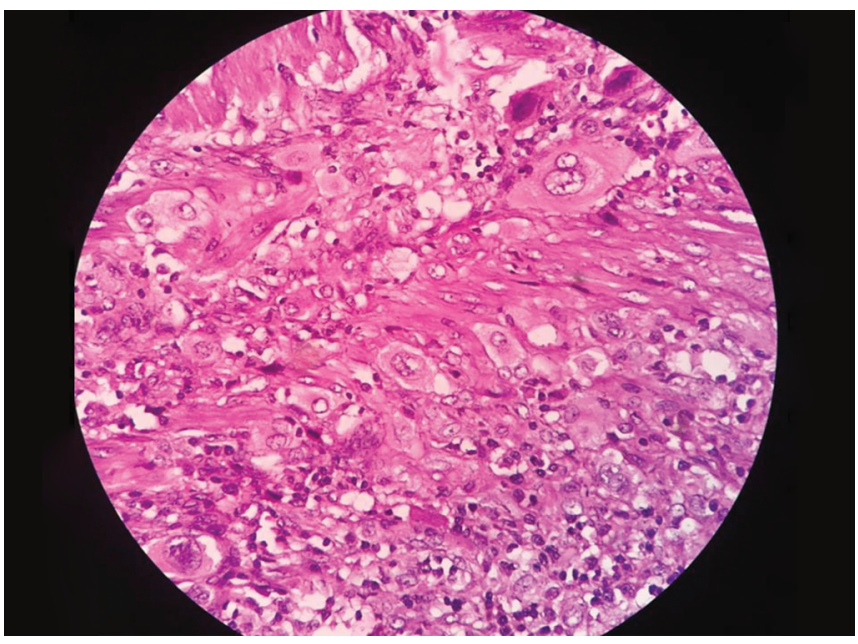

Fig. 3: $H \& E, 400 x$ showing proliferation of intermediate trophoblast cells in between myometrial tissue and causing splitting of muscles

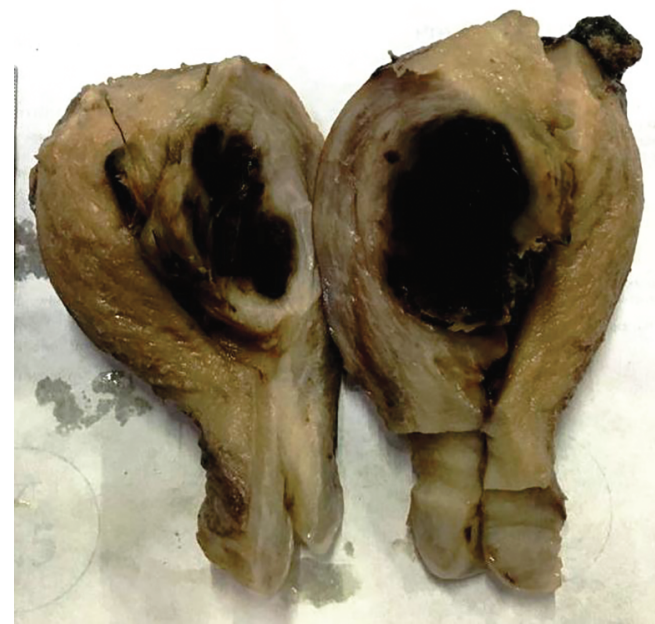

Fig. 2: Gross photo showing hemorrhagic mass involving the endometrial cavity

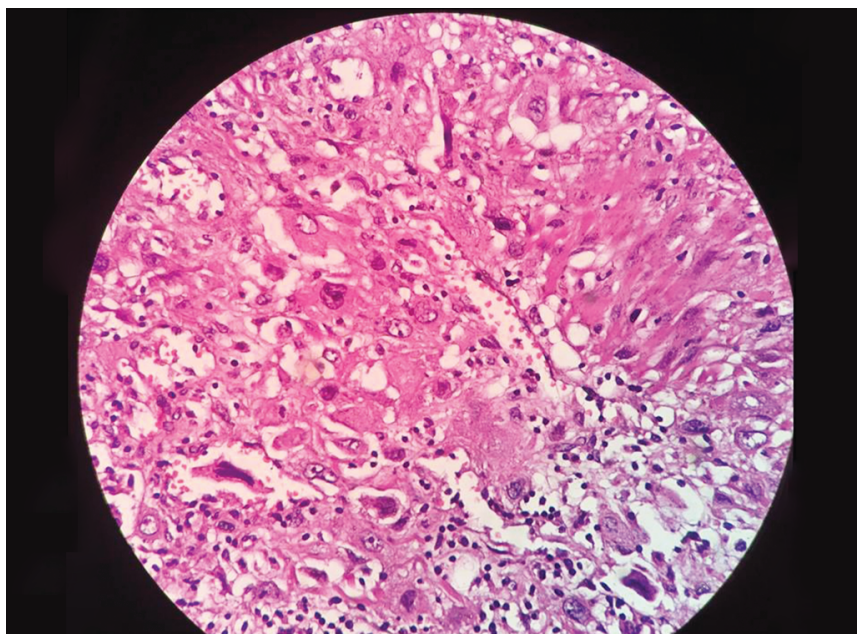

Fig. 4: $\mathrm{H}$ and $\mathrm{E}, 400 \mathrm{x}$ showing vascular wall replacement by the tumor cells

Table 1: FIGO/WHO 2000 scoring system: The total score results from addition of the individual score for each prognostic factor: low risk $\leq 6$; high risk $\geq 7$

\begin{tabular}{lcccc}
\hline Score & 0 & 1 & 2 & - \\
\hline Age (years) & $<40$ & $\geq 40$ & - & - \\
Previous pregnancy & Mole & Abortion & Pregnancy on term & $>13$ \\
$\begin{array}{l}\text { Delay between the end of pregnancy and the beginning of } \\
\text { chemotherapy (months) }\end{array}$ & $<4$ & $4-7$ & $7-13$ & $13-10^{5}$ \\
hCG before the treatment (IU/L) & $<10^{3}$ & $10^{3}-10^{4}$ & Bowel & Brain, liver \\
Metastatic sites & Lung & Kidney, spleen & -8 & $>8$ \\
Number of metastasis & 0 & $1-4$ & Mono-chemotherapy Poly-chemotherapy \\
Failure of prior chemotherapy & - & - & &
\end{tabular}


Placental Site Trophoblastic Tumor

Table 2: PSTT should be differentiated from choriocarcinoma and epithelioid trophoblastic tumor (ETT)

\begin{tabular}{|c|c|c|c|c|c|}
\hline Types of GTN & Age (years) & Pretreatment $h C G(\mathrm{~m} / \mathrm{U} / \mathrm{mL})$ & Tumor cells & Cytological atypia & Immuno-histochemistry \\
\hline PSTT & $20-63$ & $<x 10^{3}$ & $\begin{array}{l}\text { Implantation site type interme- } \\
\text { diate trophoblast }\end{array}$ & ++ & $\begin{array}{l}\text { Diffuse positivity for hPL } \\
\text { and Mel-CAM, Ki-67 index } \\
5-10 \%\end{array}$ \\
\hline $\begin{array}{l}\text { Chorio- } \\
\text { carcinoma }\end{array}$ & $29-31$ & $>10 \times 10^{3}$ & $\begin{array}{l}\text { Trimorphic pattern, villous } \\
\text { intermediate trophoblast, } \\
\text { syncytio- } \\
\text { trophoblast and cytotropho- } \\
\text { blast }\end{array}$ & +++ & $\begin{array}{c}\text { Diffuse positivity for hCG, } \\
\text { hPL and HSD3B1, } \\
\text { Ki-67 index: }>90 \%\end{array}$ \\
\hline ETT & $15-48$ & $<3 \times 10^{3}$ & $\begin{array}{c}\text { Chronic type intermediate } \\
\text { trophoblast }\end{array}$ & + & $\begin{array}{l}\text { Diffuse positivity for p63, } \\
\text { Ki-67 index: }>10 \%\end{array}$ \\
\hline
\end{tabular}

and onset of disease, the patient's age and the rate of mitosis, and on the basis of these parameters FIGO/WHO scoring system for trophoblastic tumor is done (Table 1). ${ }^{8,9}$ As the data is limited regarding its management and hence prognosis is quiet unpredictable. Metastasis is seen in about $10-35 \%$ of cases. The brain, liver, and spine were reported sites of distant metastasis as shown in the study by Hyman et al. ${ }^{7}$ Extrapulmonary metastasis is seen in kidneys and adrenal. It is very important to distinguish it from choriocarcinoma as they are less chemosensitive and due to the frequency of the tumors, treatment is not well established (Table 2).

Prognostic factors:

Independent predictors of poorer prognosis are: $:^{10}$

- Advanced FIGO stage

- Antecedent pregnancy of 48 months or more

- Presence of tumor cells with clear cytoplasm

Histological parameters that correlate with prognosis are:11

- Depth of invasion

- Tumor size

- Necrosis

- High mitosis (>5 per $10 \mathrm{HPF}$ )

\section{Conclusion}

PSTT is rare variant of GTN. The disease is unique from other GTNs because of low beta-hCG serum levels, slow growth, late-onset metastasis, and relative resistance to chemotherapy. The diagnosis should be considered clinically in patients with persistent or increased levels of serum beta hCG. Careful microscopic examination helps in reaching the correct diagnosis. Surgical treatment has the leading role in treatment, with the combination of chemotherapy in advanced cases.

\section{References}

1. Xianling Z, Liu X, Tian Q, et al. Placental site trophoblastic tumor: a case report and literature review. Intractable Rare Dis Res 2015;4(3):147-151. DOI:10.5582/irdr.2015.01013

2. Fathaddin AA, Arafah MA. A malignant placental site trophoblastic tumor of the uterus with multiple metastases: a case report of a rare tumor showing an aggressive behaviour. Indian J pathol Microbiol 2019;62(1):142-145. DOI: 10.4103/IJPM.IJPM_45_18

3. Manu V, Pillai AK, Kumar S, et al. Placental site trophoblastic tumor with metastasis - a case report. Med J Armed Forces India 2013;69(1):69-70. DOI: 10.1016/j.mjafi.2012.01.003

4. Behtash N, Karimi ZM. Placental site trophoblastic tumor. J cancer Res Clin Oncol 2008;134(1):1-6. DOI: 10.1007/978-3-540-47648-1_4591

5. Luiza JW, Taylor SE, Gao FF, et al. Placental site trophoblastic tumor: immunohistochemistry algorithm key to diagnosis and review of literature. Gynecol Oncol Case Rep 2014;7:13-15. DOI: 10.1016/j. gynor.2013.11.001

6. de la Joliniere JB, Khomsi F, et al. Placental site trophoblastic tumor: a case report and review of the literature. Front Surg 2014;1:31. DOI: 10.3389/fsurg.2014.00031

7. Hyman DM, Bakios L, Gualtiere G, et al. Placental site trophoblastic tumor: analysis of presentation, treatment, and outcome. Gynecoln Oncol 2013;129(1):58-62. DOI: 10.1016/j.ygyno.2012.12.029

8. SeckI MJ, Sebire NJ, Fisher RA, et al. Gestational trophoblastic disease: ESMO Clinical Practice Guidelines for diagnosis, treatment and follow-up. Ann Oncol 2013;24 Suppl 6:vi39-50.DOI: 10.1093/annonc/ mdt345

9. Ngan H, Kohorn El, Cole LA, et al. Trophoblastic disease. Int J Gynaecol Obstet 2012;119 Suppl 2:S130-136. DOI: 10.1016/S00207292(12)60026-5

10. Schmid $P$, Nagai $Y$, Agarwal $R$, et al. Prognostic markers and long-term outcome of placental-site trophoblastic tumours: a retrospective observational study. Lancet 2009; 374(9683):48-55. DOI: 10.1016/ S0140-6736(09)60618-8.

11. Gynecol Oncol 2006;100:511, Kurman: WHO Classification of Tumours of the Female Reproductive Organs, 4th Edition, 2014. 